\title{
EXCESS AND DEVIATIONS PROPERTIES FOR THE BINARY SOLVENT MIXTURES OF TETRAHYDROFURFURYL ALCOHOL WITH SOME AROMATIC HYDROCARBONS AT 298.15K
}

\author{
DHAFIR TAMWEEN AJEEL AL-HEETIMI ${ }^{\text {a* }}$, \\ ZAINAB ABBAS AL-DULAIMYa, ASAL AHMED AL-JAWARYa, \\ OMAR SABEEH AL-KHAZRAJYa
}

\begin{abstract}
In this work, excess properties (e.g. excess molar volume $\left(\mathrm{V}^{\mathrm{E}}\right)$, excess viscosity $\left(\Pi^{\mathrm{E}}\right)$, excess Gibbs free energy of activation of viscos flow $\left(\Delta G^{* E}\right)$ and molar refraction changes $\left(\Delta n_{D}\right)$ of binary solvent mixtures of tetrahydrofurfuryl alcohol (THFA) with aromatic hydrocarbons (benzene, toluene and $p$-xylene) have been calculated. This was achieved by determining the physical properties including density $\rho$, viscosity $\Pi$ and refraction index nD of liquid mixtures at $298.15 \mathrm{~K}$. Results of the excess parameters and deviation functions for the binary solvent mixtures at $298.15 \mathrm{~K}$ have been discussed by molecular interactions that occur in these mixtures. Generally, parameters showed negative values and have been found to fit well to Redlich-Kister equation which has been used to obtain the coefficients and evaluate the standard error.
\end{abstract}

Keywords: Binary systems, Tetrahydrofurfuryl alcohol, Deviations and excess properties, Density, Viscosity.

\section{INTRODUCTIONS}

Interest in studying the theoretical and experimental properties of solvents mixtures has been significantly increased in the last two decades. The thermodynamic and transport information (e.g. fluids flow, heat and mass transfer) of mixtures systems are important in many chemical industries,

a University of Baghdad, College of Education for pure science Ibn-Al-Haitham, Department of Chemistry, Baghdad, Iraq.

*Corresponding Author: E-mail: dhafir1973@gmail.com;

E-mail: dhafir.t.a@ihcoedu.uobaghdad.edu.iq 
solution theories and biological processes [1-4]. Moreover, for profound understanding the interaction properties between component molecules of liquid mixture, in terms of nature, strength of interaction and behavior of solution, the experimental excess properties are very important [5-8].

Tetrahydrofurfuryl alcohol (THFA), benzene, toluene and p-xylene are widely used in chemical industries. These solvents have been used in fuel, perfumes, cosmetics, lubricants, paints, dyes, printing ink, drugs, gums, resins, etc. $[9,10]$. The excess properties for these organic solvents are useful in investigating the molecular motion and packing, and interaction in their mixtures [11].

In this study, physical properties such as density, viscosity and refractive index were determined over a range of binary systems ((THFA+ Benzene), (THFA + Toluene) and (THFA+P-Xylene)) concentrations at 298.15K. Excess molar properties including $V^{E} \eta^{E}, \Delta G^{*}$ and refractive index deviation were derived. Up to our knowledge, those binary solvent mixtures have not been studied for $V E, \eta^{E}, \Delta G^{*}$, and $\Delta n_{D}$ at any temperature.

\section{RESULTS AND DISCUSSION}

In this work the retrieved data from experimentally obtained density $(\rho)$ for binary systems (THFA + benzene, THFA + toluene and THFA + pxylene) at $298.15 \mathrm{~K}$ were used to calculate $\mathrm{VE}^{\mathrm{E}}$ for binary solvent mixtures using following equation (1) [12]:

$$
\mathrm{V}^{\mathrm{E}}=\frac{X_{1} M_{1}+X_{2} M_{2}}{\rho_{12}}-\frac{X_{1} M_{1}}{\rho_{1}}-\frac{X_{2} M_{2}}{\rho_{2}}
$$

where $X_{1}$ and $X_{2}$ are the mole fractions, $M_{1}$ and $M_{2}$ are the molar masses and $\rho_{1}, \rho_{2}$ are densities of solvents 1 and 2 ; while $\rho_{12}$ is the density of the mixture. Values of $\mathrm{VE}$ and $\rho$ of the binary solvent systems at a range of mole fractions of THFA with benzene, toluene and p-xylene are presented in Table 1. Excess viscosities were obtained using equation (2) [13]:

$$
\eta^{\mathrm{E}}=\eta_{12}-\left(\mathrm{x}_{1} \eta_{1}+\mathrm{X}_{2} \eta_{2}\right)
$$

where $\eta_{1}$ and $\eta_{2}$ are viscosities of solvents 1 and 2 , respectively, $\eta_{12}$ is the viscosity of mixture. The results are listed in Table 1.

Equation 3 was used to calculate $\left(\Delta \mathrm{G}^{*} \mathrm{E}\right)$ [14]:

$$
\Delta \mathrm{G}^{* \mathrm{E}}=\mathrm{RT}\left[\ln \left(\mathrm{\eta}_{12} \mathrm{~V}_{12}\right)-\left(\mathrm{X}_{1} \ln \eta_{1} \mathrm{~V}_{1}\right)-\left(\mathrm{X}_{2} \ln \eta_{2} \mathrm{~V}_{2}\right)\right]
$$

where $R$ is gases universal constant and $T$ is the absolute temperature $(K)$. $\mathrm{V}_{1}, \mathrm{~V}_{2}$ are the molar volumes of solvents 1 and 2 ; while $\mathrm{V}_{12}$ is the molar volume for binary system. Table 1 shows the values of $\Delta \mathrm{G}^{* \mathrm{E}}$ determined from equation $3 . V_{12}$ has been obtained from the below equation: 


$$
\mathrm{V}_{12}=\left(\mathrm{X}_{1} \mathrm{M}_{1}+\mathrm{X}_{2} \mathrm{M}_{2}\right) / \rho_{12}
$$

Molar refraction $\left(n_{D}\right)$ was calculated using the Lorentz-Lorenz equations $(5,6$, and 7$)$ [15]

$$
\begin{aligned}
& \mathrm{n}_{\mathrm{D}}=\left(\frac{n_{12}^{2}-1}{\mathrm{n}_{12}^{2}+2}\right) \frac{\mathrm{X} 1 \mathrm{M} 1+\mathrm{X} 2 \mathrm{M} 2}{\rho_{12}} \\
& \mathrm{n}_{\mathrm{D} 1}=\left(\frac{\mathrm{n}_{1}^{2}-1}{\mathrm{n}_{1}^{2}+2}\right) \frac{\mathrm{X} 1 \mathrm{M} 1}{\rho_{1}} \\
& \mathrm{n}_{\mathrm{D} 2}=\left(\frac{\mathrm{n}_{2}^{2}-1}{\mathrm{n}_{2}^{2}+2}\right) \frac{\mathrm{X} 2 \mathrm{M} 2}{\rho_{2}}
\end{aligned}
$$

where $n_{12}$ is the refractive index of the mixture; whereas $n_{1}$ and $n_{2}$ are the refractive index of solvent 1 and 2 , respectively. The deviation from a molar fraction average of the molar refraction was computed according to the equation (8) $[16,17]$ :

$$
\Delta \mathrm{n}_{\mathrm{D}}=\mathrm{n}_{\mathrm{D}}-\mathrm{X}_{1} \mathrm{n}_{\mathrm{D} 1}-\mathrm{X}_{2} \mathrm{n}_{\mathrm{D} 2}
$$

where $\Delta n_{D}$ represents the deviation value from molar fraction. Table 1 lists experimental $\mathrm{n}_{\mathrm{D}}$ and $\Delta \mathbf{n}_{\mathrm{D}}$ for the binary solvent mixtures.

For binary solvent mixtures, the excess function was determined using Redlich-Kister model equation (9) [18]:

$$
\mathrm{X}^{\mathrm{E}}=\mathrm{X}_{\mathrm{i}} \mathrm{X}_{\mathrm{j}} \sum_{\mathrm{K}=0}^{\mathrm{n}} \mathrm{A}_{\mathrm{K}}\left(\mathrm{X}_{\mathrm{i}}-\mathrm{X}_{\mathrm{j}}\right)^{\mathrm{k}}
$$

where $X^{E}$ may represent $V^{E}, \eta^{E}, \Delta G^{*}$ or $\Delta n_{D} . X_{i}$ and $X_{j}$ are the mole fractions of the components $i$ and $j$, respectively. $n$ is the degree of polynomial expansion and $A_{k}$ denotes the polynomial coefficients. The equation (10) was used to calculate standard deviation $(\sigma)$ for the excess parameters [19]:

$$
\sigma=\left[\sum\left(\mathrm{X}_{\text {exp }}^{\mathrm{E}}-\mathrm{X}_{\text {calc }}^{\mathrm{E}}\right)^{2} /(\mathrm{M}-\mathrm{n})\right]^{1 / 2}
$$

where $M$ is the number of data points and $n$ is the number of estimated parameters. The values of these coefficients and the standard deviation are given in Table 2.

For all the studied systems, the negative values of $V^{E}, \eta^{E}, \Delta G^{*} E, \Delta n_{D}$ follow the order: Benzene > Toluene > p-xylene. Fig. 1 shows the deviations in molar volume for all the systems (THFA+ benzene), (THFA+ toluene) and (THFA+ $p$-xylene). The obtained negative values of $\mathrm{V}^{\mathrm{E}}$ can be attributed to the interactions of dipolar-induced forces between the benzene ring of the aromatic hydrocarbons and hydroxyl group $(\mathrm{OH})$ or oxygen of the THFA, which results the formation of electron donor-acceptor complexes and the breaking of the self-associations existing in pure solvents $[20,21]$. 
DHAFIR TAMWEEN AJEEL AL-HEETIMI, ZAINAB ABBAS AL-DULAIMY, ASAL AHMED AL-JAWARY, OMAR SABEEH AL-KHAZRAJY

Table 1. Experimentally obtained and calculated values of density, viscosity and refractive index, $V E, n^{E}, \Delta G^{*} E, n_{D}$ and $\Delta n_{D}$ for binary solvent mixtures of THFA+benzene, THFA+ toluene and THFA+ p-xylene at 298.15K.

\begin{tabular}{|c|c|c|c|c|c|c|c|}
\hline \multicolumn{7}{|c|}{$\mathrm{X}_{\mathbf{1}}$ THFA $+\mathrm{X}_{\mathbf{2}}$ benzene at 298.15K } \\
\hline $\mathrm{X}_{\mathbf{1}}$ & $\rho\left({\left.\mathrm{g} . \mathrm{cm}^{-3}\right)}^{\mathrm{E}} \mathrm{V}^{\mathrm{E}} \mathrm{mol}^{-1}\right.$ & $\eta$ & $\eta^{\mathrm{E}} \mathrm{mpa} . \mathrm{S}$ & $\Delta \mathrm{G}^{\mathrm{E}}\left({\left.\mathrm{J} . \mathrm{mol}^{-1}\right)} \mathrm{n}_{\mathrm{D}}\right.$ & $\mathrm{n}_{\mathrm{D}}$ \\
\hline 0.0000 & 0.87372 & 0.00000 & 0.59951 & 0.00000 & 0.0000 & 1.4975 & 0.0000 \\
\hline 0.0867 & 0.89294 & -0.11763 & 0.65845 & -0.08836 & -218.2600 & 1.4882 & -0.2377 \\
\hline 0.2012 & 0.91623 & -0.16936 & 0.81019 & -0.12150 & -299.6432 & 1.4754 & -0.5832 \\
\hline 0.3078 & 0.93673 & -0.19441 & 0.99374 & -0.14121 & -348.0611 & 1.4664 & -0.7895 \\
\hline 0.3622 & 0.94663 & -0.18579 & 1.10746 & -0.14713 & -362.5572 & 1.4636 & -0.8175 \\
\hline 0.5033 & 0.97132 & -0.16189 & 1.48353 & -0.15119 & -372.4340 & 1.4581 & -0.8077 \\
\hline 0.5528 & 0.97965 & -0.15214 & 1.65007 & -0.14877 & -366.4779 & 1.4571 & -0.7589 \\
\hline 0.6664 & 0.99804 & -0.11675 & 2.13172 & -0.13130 & -323.4082 & 1.4552 & -0.6238 \\
\hline 0.9082 & 1.02332 & -0.06816 & 3.09948 & -0.10213 & -251.8803 & 1.4545 & -0.3136 \\
\hline 1.0000 & 1.04761 & 0.00000 & 4.89883 & 0.00000 & 0.0000 & 1.4532 & 0.0000 \\
\hline
\end{tabular}

\begin{tabular}{|c|c|c|c|c|c|c|c|}
\hline \multicolumn{7}{|c|}{$\mathbf{X}_{1}$ THFA + $\mathbf{X}_{2}$ toluene at $298.15 K$} \\
\hline $\mathbf{X}_{1}$ & $\rho\left({\left.\mathrm{g} . \mathrm{cm}^{-3}\right)}^{-1}\right.$ & $\mathrm{V}^{\mathrm{E}} \mathrm{cm}^{3} \mathrm{~mol}^{-1}$ & $\eta$ & $\eta^{\mathrm{E}} \mathrm{mpa} . \mathrm{s}$ & $\Delta \mathrm{G}^{\mathrm{E}}\left(\mathrm{J} . \mathrm{mol}^{-1}\right)$ & $\mathrm{nD}$ & $\Delta \mathrm{n} \mathrm{D}$ \\
\hline 0.0000 & 0.86224 & 0.00000 & 0.55464 & 0.00000 & 0.0000 & 1.4950 & 0.0000 \\
\hline 0.0801 & 0.87733 & -0.17517 & 0.55817 & -0.16815 & -416.0727 & 1.4855 & -0.3714 \\
\hline 0.2024 & 0.89945 & -0.27578 & 0.67662 & -0.24213 & -598.5265 & 1.4750 & -0.7081 \\
\hline 0.3004 & 0.91712 & -0.30678 & 0.82295 & -0.25982 & -641.8989 & 1.4670 & -0.9415 \\
\hline 0.3968 & 0.93436 & -0.28668 & 1.01161 & -0.26343 & -650.4906 & 1.4624 & -0.9856 \\
\hline 0.5022 & 0.95335 & -0.24312 & 1.27016 & -0.26543 & -655.2431 & 1.4581 & -0.9821 \\
\hline 0.5867 & 0.96872 & -0.19668 & 1.55083 & -0.24986 & -616.8046 & 1.4562 & -0.8887 \\
\hline 0.7005 & 0.98983 & -0.13909 & 2.08992 & -0.19942 & -492.1386 & 1.4553 & -0.6653 \\
\hline 0.7915 & 1.00704 & -0.09509 & 2.64994 & -0.16026 & -395.4876 & 1.4547 & -0.4714 \\
\hline 0.8996 & 1.02791 & -0.04847 & 3.57807 & -0.09546 & -235.6671 & 1.4539 & -0.2334 \\
\hline 1.0000 & 1.04761 & 0.00000 & 4.89883 & 0.00000 & 0.0000 & 1.4532 & 0.0000 \\
\hline
\end{tabular}


EXCESS AND DEVIATIONS PROPERTIES FOR THE BINARY SOLVENT MIXTURES OF TETRAHYDROFURFURYL ALCOHOL WITH SOME AROMATIC HYDROCARBONS AT 298.15K

\begin{tabular}{|c|c|c|c|c|c|c|c|}
\hline \multicolumn{7}{|c|}{$\mathbf{X}_{1}$ THFA $+\mathbf{X}_{2}$ p-xylene at 298.15K } \\
\hline $\mathbf{X}_{1}$ & $\rho\left(\mathrm{g}_{\mathrm{cm}} \mathrm{cm}^{-3}\right)$ & $\mathrm{V}^{\mathrm{E}} \mathrm{cm}^{3} \mathrm{~mol}^{-1}$ & $\eta$ & $\eta^{\mathrm{E}} \mathrm{mpa} . \mathrm{s}$ & $\Delta \mathrm{G}^{* \mathrm{E}}\left(\mathrm{J} . \mathrm{mol}^{-1}\right)$ & $\mathrm{n}_{\mathrm{D}}$ & $\Delta \mathrm{n}_{\mathrm{D}}$ \\
\hline 0.0000 & 0.85676 & 0.00000 & 0.61225 & 0.00000 & 0.0000 & 1.4945 & 0.0000 \\
\hline 0.1074 & 0.87474 & -0.20439 & 0.66272 & -0.14414 & -350.8699 & 1.4859 & -0.5063 \\
\hline 0.2045 & 0.89176 & -0.38483 & 0.73091 & -0.24813 & -604.0360 & 1.4773 & -0.9615 \\
\hline 0.2921 & 0.90681 & -0.42023 & 0.84477 & -0.28553 & -693.5423 & 1.4710 & -1.2382 \\
\hline 0.3968 & 0.92537 & -0.43209 & 1.02825 & -0.30671 & -743.5405 & 1.4669 & -1.3145 \\
\hline 0.5168 & 0.94742 & -0.40192 & 1.29614 & -0.32474 & -787.1356 & 1.4629 & -1.2905 \\
\hline 0.6108 & 0.96535 & -0.35118 & 1.59703 & -0.31146 & -754.8408 & 1.4602 & -1.1920 \\
\hline 0.7811 & 0.99944 & -0.20241 & 2.43108 & -0.24543 & -595.6440 & 1.4577 & -0.7568 \\
\hline 0.8856 & 1.02173 & -0.10211 & 3.30304 & -0.15625 & -379.6321 & 1.4548 & -0.4554 \\
\hline 1.0000 & 1.04761 & 0.00000 & 4.89883 & 0.00000 & 0.0000 & 1.4532 & 0.0000 \\
\hline
\end{tabular}

The results of deviations in viscosity $\left(\Pi^{\mathrm{E}}\right)$ for mixtures (THFA+ benzene), (THFA+ toluene) and (THFA+ p-xylene) are illustrated in Fig. 2. Interaction between components molecules believed to be due dispersion or weak dipole-dipole forces [22]. Moreover, THFA contains molecules with high polarity while aromatic hydrocarbon are non-polar molecules having $\pi$ electrons on the ring. THFA molecules would induce a small dipole moment in the aromatic hydrocarbon molecule when mixed. A formation of a weak dipoleinduced dipole interaction between the component molecules is also expected. In addition, donor acceptor interaction between $\pi$-electrons of benzene ring and oxygen of $\mathrm{O}-\mathrm{H}$ group of THFA results in negative values of $\eta^{\mathrm{E}}$ [11].

The plots of $\Delta G^{*} E$ versus mole fractions $\left(X_{1}\right)$ at $298.15 K$ for all the three binary systems (THFA + benzene, THFA + toluene and THFA + pxylene) are presented in Fig.3. Values of $\Delta G^{*} E$ were found to be negative for all the systems under study. The experimentally obtained negative $\Delta \mathrm{G}^{*} \mathrm{E}$ and $\eta^{\mathrm{E}}$ values for all binary solvents mixtures show weak interactions between unlike molecules and indicate that flow is easier for the binary solvent mixtures when compared with that of pure solvents [23,24].

The deviations in $\Delta \mathrm{n}_{\mathrm{D}}$ (molar refraction) was found to be negative for all binary systems over the composition range at investigated temperature (Fig.4). Generally, the negative values of $\Delta n_{D}$ suggest weak interactions between the component molecules in the system [15]. For all binary solvent 
DHAFIR TAMWEEN AJEEL AL-HEETIMI, ZAINAB ABBAS AL-DULAIMY, ASAL AHMED AL-JAWARY, OMAR SABEEH AL-KHAZRAJY

mixtures, the interactions of self-association are stronger than the specific interaction of unlike molecules, and the average interaction strength in mixture is weaker than that in the pure solvents.

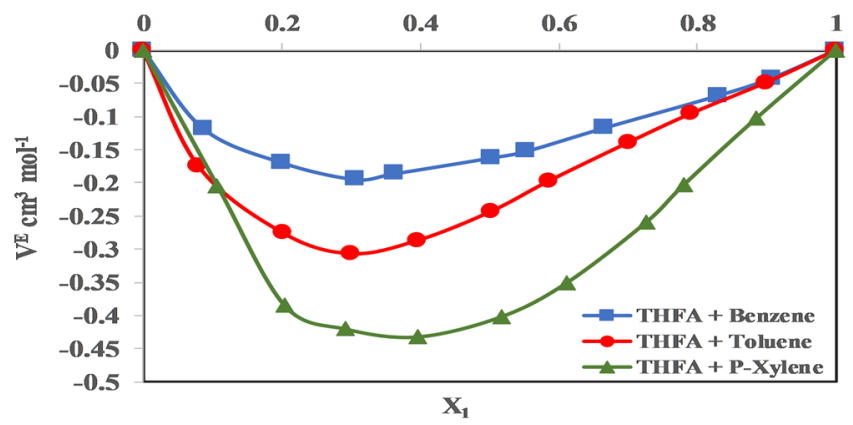

Figure 1. $V^{E}$ versus $X_{1}$ for $(\mathbf{\square}) X_{1} \operatorname{THFA}+X_{2}$ benzene, $(\bullet) X_{1} \operatorname{THFA}+$ $\mathrm{X}_{2}$ toluene and $(\boldsymbol{\Delta}) \mathrm{X}_{1} \mathrm{THFA}+\mathrm{p}$-xylene at $298.15 \mathrm{~K}$.

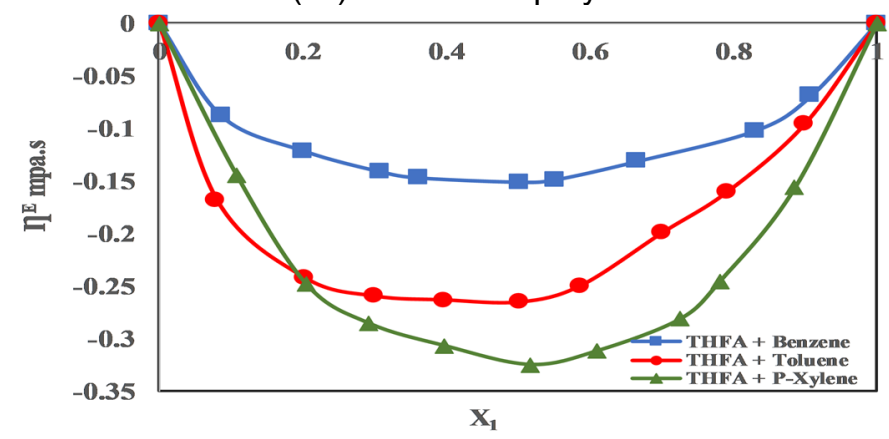

Figure 2. $\eta^{E}$ versus $X_{1}$ for $(\bullet) X_{1}$ THFA+ $X_{2}$ benzene, $(\bullet) X_{1}$ THFA+ $\mathrm{X}_{2}$ toluene and $(\mathbf{\Delta}) \mathrm{X}_{1} \mathrm{THFA}+\mathrm{X}_{2} \mathrm{p}$-xylene at 298.15K.

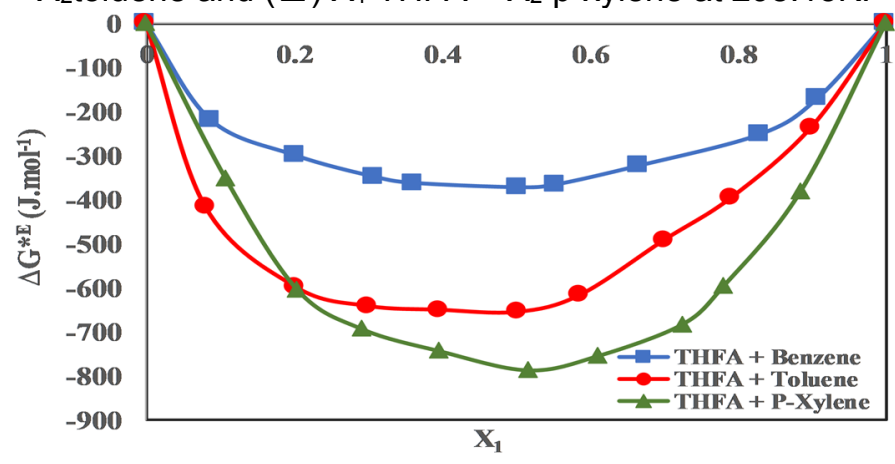

Figure 3. $\Delta G^{*}$ versus $X_{1}$ for $(\bullet) X_{1}$ THFA $+X_{2}$ benzene, $(\bullet) X_{1}$ THFA+ $\mathrm{X}_{2}$ toluene and $(\boldsymbol{\Delta}) \mathrm{X}_{1}$ THFA $+\mathrm{X}_{2} \mathrm{p}$-xylene at 298.15K. 
EXCESS AND DEVIATIONS PROPERTIES FOR THE BINARY SOLVENT MIXTURES OF TETRAHYDROFURFURYL ALCOHOL WITH SOME AROMATIC HYDROCARBONS AT 298.15K

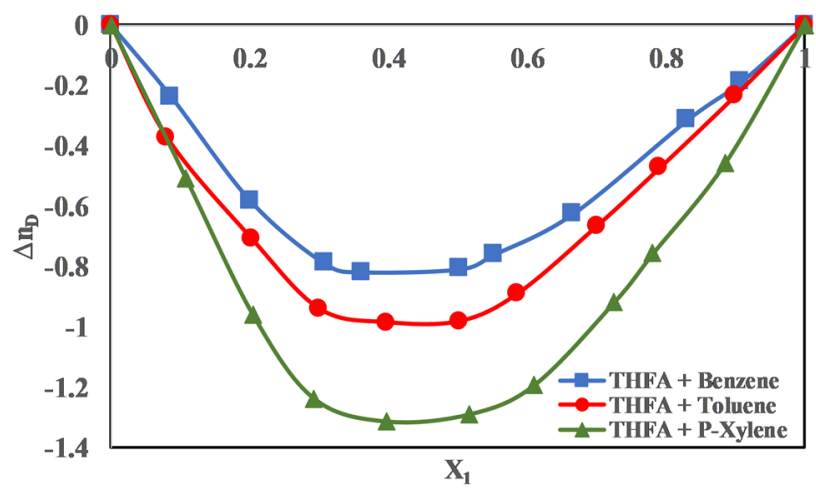

Figure 4. Excess refractive index versus $X_{1}$ for $(\square) X_{1}$ THFA $+X_{2}$ benzene, $(\bullet) \mathrm{X}_{1} \mathrm{THFA}+\mathrm{X}_{2}$ toluene and $(\boldsymbol{\Delta}) \mathrm{X}_{1} \mathrm{THFA}+\mathrm{X}_{2} \mathrm{p}$-xylene at 298.15K.

Table 2. Polynomial coefficients $\left(A_{k}\right)$ and standard deviations $(\sigma)$ for binary solvent mixtures at $298.15 \mathrm{~K}$.

\begin{tabular}{|c|c|c|c|c|c|}
\hline Function & System & $A_{0}$ & $A_{1}$ & $\mathrm{~A}_{2}$ & $\sigma$ \\
\hline VE $\left(\mathrm{cm} 3 \cdot \mathrm{mol}^{-1}\right)$ & THFA + Benzene & -0.64840 & 0.50722 & -0.41527 & 0.00005 \\
\hline VE $\left(\mathrm{cm} 3 \cdot \mathrm{mol}^{-1}\right)$ & THFA + Toluene & -0.96620 & 0.99681 & -0.58565 & 0.02326 \\
\hline VE $\left(\mathrm{cm} 3 \cdot \mathrm{mol}^{-1}\right)$ & THFA + P-Xylene & -1.65665 & 0.87340 & -0.07943 & 0.02937 \\
\hline Function & System & $A_{0}$ & $A_{1}$ & $A_{2}$ & $\sigma$ \\
\hline$\eta^{\mathrm{E}}$ (mPa.s) & THFA + Benzene & -0.58614 & 0.07922 & -0.45357 & 0.02414 \\
\hline$\eta^{\mathrm{E}}$ (mPa.s) & THFA + Toluene & -1.02289 & 0.43810 & -0.70071 & 0.03616 \\
\hline$\eta^{\mathrm{E}}$ (mPa.s) & THFA + P-Xylene & -1.29209 & 0.00408 & -0.47842 & 0.01902 \\
\hline Function & System & $A_{0}$ & $A_{1}$ & $\mathrm{~A}_{2}$ & $\sigma$ \\
\hline$\Delta \mathrm{n}_{\mathrm{D}}\left(\mathrm{cm}^{3} \cdot \mathrm{mol}^{-1}\right)$ & THFA + Benzene & -3.26617 & 1.03140 & 0.76222 & 0.03357 \\
\hline$\Delta \mathrm{n}_{\mathrm{D}}\left(\mathrm{cm}^{3} \cdot \mathrm{mol}^{-1}\right)$ & THFA + Toluene & -3.89318 & 1.43064 & 0.49336 & 0.03873 \\
\hline$\Delta \mathrm{n}_{\mathrm{D}}\left(\mathrm{cm}^{3} \cdot \mathrm{mol}^{-1}\right)$ & THFA + P-Xylene & -5.29561 & 1.18722 & 0.44150 & 0.03461 \\
\hline Function & System & $A_{0}$ & $A_{1}$ & $A_{2}$ & $\sigma$ \\
\hline$\Delta \mathrm{G}^{* \mathrm{E}}\left(\mathrm{J}^{\left.\mathrm{m} \mathrm{mol}^{-1}\right)}\right.$ & THFA + Benzene & -1443.65 & 196.1852 & -1124.19 & 1.20126 \\
\hline$\Delta \mathrm{G}^{* \mathrm{E}}\left(\mathrm{J}^{\mathrm{mol}} \mathrm{mol}^{-1}\right)$ & THFA + Toluene & -2524.99 & 1086.265 & -1737.40 & 1.80019 \\
\hline$\Delta \mathrm{G}^{\star \mathrm{E}}\left(\mathrm{J}^{\mathrm{m} \mathrm{mol}^{-1}}\right)$ & THFA + P-Xylene & -3131.71 & 15.89403 & -1185.48 & 0.94697 \\
\hline
\end{tabular}


DHAFIR TAMWEEN AJEEL AL-HEETIMI, ZAINAB ABBAS AL-DULAIMY, ASAL AHMED AL-JAWARY, OMAR SABEEH AL-KHAZRAJY

\section{EXPERIMENTAL SECTION}

\section{Chemicals}

All solvents in this study (THFA, benzene, toluene and p-xylene) were purchased from Sigma-Aldrich and with purity of $\geq 99 \%$, therefore, no further purifications were needed. Density $\boldsymbol{\rho}$, viscosity $\eta$ and refractive index $\mathrm{n}_{\mathrm{D}}$ for solvents have been checked and examined against those listed in the literature (Table 3).

\section{Measurements}

The densities $(\rho)$ were calculated (an average of three replicates) with accuracy of $\left( \pm 0.00001 \mathrm{~g} \mathrm{~cm}^{-3}\right)$ using a digital density meter (Anton paar, Model DMA 60/602). A controlled temperature suspended-level Ubbelohde viscometer was used for the measurement of viscosity $(\eta)$ under atmospheric pressure at $298.15 \pm 0.01 \mathrm{~K}$.

The determinations of refractive indices for pure solvents and their binary solvent mixtures were performed using a digital Abbe refractometer (model: BOE 32400). For refractometer calibration, double distilled water used at 298.15.

Table 3. Experimental and literature physical properties [density ( $\rho)$, viscosity (П) and refractive index $\left.\left(\mathrm{n}_{\mathrm{D}}\right)\right]$ of pure solvents at $298.15 \mathrm{~K}$.

\begin{tabular}{|c|c|c|c|c|c|c|c|}
\hline \multirow{2}{*}{ Compound } & \multirow{2}{*}{$\mathrm{T} / \mathrm{K}$} & \multicolumn{2}{|c|}{$\rho\left(\mathrm{g}^{\left.\mathrm{c} \mathrm{cm}^{-3}\right)}\right.$} & \multicolumn{2}{|c|}{$\eta$ mpa.s } & \multicolumn{2}{|c|}{$\mathrm{nd}$} \\
\hline & & Exp. & Lit. [ref] & Exp. & Lit. [ref] & Exp. & Lit. [ref] \\
\hline THFA & 298.15 & 1.04761 & $1.04761^{[25]}$ & 4.89883 & $4.89883^{[25]}$ & 1.4532 & $1.45322^{[25]}$ \\
\hline Benzene & 298.15 & 0.87372 & $\begin{array}{c}0.87357^{[26]} \\
0.87361^{[27]} \\
0.87360^{[28]} \\
0.87342^{[29]} \\
\end{array}$ & 0.59951 & $\begin{array}{c}0.6038^{[26]} \\
0.604[28]\end{array}$ & 1.4975 & $\begin{array}{l}1.4980^{[27]} \\
1.4971^{[29]}\end{array}$ \\
\hline Toluene & 298.15 & 0.86224 & $\begin{array}{c}0.86301^{[26]} \\
0.86236^{[27]} \\
0.86220^{[28]} \\
0.86226^{[29]}\end{array}$ & 0.55464 & $\begin{array}{c}0.5540[26] \\
0.556[28]\end{array}$ & 1.4950 & $\begin{array}{l}1.4942^{[27]} \\
1.4931^{[29]}\end{array}$ \\
\hline p-xylene & 298.15 & 0.85676 & $\begin{array}{l}0.85670^{[26]} \\
0.85682^{[27]} \\
0.85662^{[28]} \\
0.85670^{[29]}\end{array}$ & 0.61225 & $\begin{array}{c}0.6078^{[26]} \\
0.611^{[28]}\end{array}$ & 1.4945 & $\begin{array}{l}1.4933^{[27]} \\
1.4926^{[29]}\end{array}$ \\
\hline
\end{tabular}

Exp.: experimental, Lit.: literature, [ref]: reference 
EXCESS AND DEVIATIONS PROPERTIES FOR THE BINARY SOLVENT MIXTURES OF

TETRAHYDROFURFURYL ALCOHOL WITH SOME AROMATIC HYDROCARBONS AT 298.15K

\section{CONCLUSIONS}

The values of $\rho, \eta$, and $n_{D}$ were calculated in binary solvent mixtures THFA with benzene, toluene and $p$-xylene over a range of mole fractions. Various excess properties like $V E, \eta^{E}, \Delta G^{*} E, \Delta n_{D}$ were calculated from experimentally obtained thermodynamic values. For the binary solvent mixtures studied, benzene showed the most negative values of $\left(V^{E}, \eta^{E}, \Delta G^{*} E\right.$, $\left.\Delta \mathrm{n}_{\mathrm{D}}\right)$ while $p$-xylene showed the least.

The experimental values of $V^{E}, \eta^{E}, \Delta G^{*} E, \Delta n_{D}$ were fitted well to Redlich-Kister equation. For all binary solvent mixtures, the interactions of self-association are stronger than the specific interaction of unlike molecules, while, the average interaction strength in mixture is weaker than that in the pure solvents.

\section{ACKNOWLEDGMENTS}

The authors wish to thank the College of Education for pure Science Ibn Al-Haitham for providing the chemicals.

\section{REFERENCES}

1. B. García, R. Alcalde, J.M. Leal, J.S. Matos, Journal of the Chemical Society, Faraday Transactions, 1996, 92(18), 3347.

2. Y. Maham, C.N. Liew, A. E. Mather, Journal of solution chemistry, 2002, 31(9), 743.

3. R. M. Pires, H.F. Costa, A.G.M. Ferreira, I.M.A. Fonseca, Journal of Chemical \& Engineering Data, 2007,52, 1240.

4. M.S. Lakshmi, R.R. Raju, C. Rambabu, GV. R. Rao and K. Narendra, Research and Reviews: Journal of Chemistry, 2013, 2(1),12.

5. P. Anila, K.R. Reddy, G.S. Rao, P.V.S. Sairam, D. Ramachandran,C. Rambabu, Thermochimica Acta, 2015, 620, 1.

6. M.N. Sovilj, Journal of Chemical \& Engineering Data, 1995, 40(5), 1058.

7. F. Giro, M.F. Goncalves, A.G.M. Ferreira, I.M.A. Fonseca, Fluid phase equilibria, 2003, 204, 217.

8. Z.A. AL-Dulaimy, D.T. AL-Heetimi, H.S. Khalaf, A.M. Abbas, Oriental Journal of Chemistry, 2018, 34(4), 2074.

9. H. Yilmaz, Turkish Journal of Physics, 2002, 26(3), 243. 
DHAFIR TAMWEEN AJEEL AL-HEETIMI, ZAINAB ABBAS AL-DULAIMY, ASAL AHMED AL-JAWARY, OMAR SABEEH AL-KHAZRAJY

10. A. Boruń, M. Żurada, A. Bald, Journal of thermal analysis and calorimetry, 2010, 100(2), 707.

11. S. Sharma, K. Thakkar, P. Patel, M. Makavana, Advances in Physical Chemistry, 2013, 2013, 1.

12. K.R. Reddy, D.B.K. Kumar, G.S. Rao, P. Anila, C. Rambabu, Thermochimica Acta, 2014, 590, 116.

13. M. Yasmin, M. Gupta, Journal of solution chemistry, 2011,40(8),1458.

14. A.S. Al-Jimaz, J.A. Al-Kandary, A.H.M. Abdul-Latif, Fluid Phase Equilib.,2004, 218(2), 247.

15. P. Brocos, Á. Piñeiro, R. Bravo, A. Amigo, Physical Chemistry Chemical Physics, 2003, 5(3), 550.

16. T.M. Aminabhavi, H.T. Phayde, R.S. Khinnavar, B. Gopalakrishna, K.C. Hansen, Journal of Chemical \& Engineering Data, 1994, 39(2), 251.

17. T.M. Aminabhavi, B. Gopalakrishna, Journal of Chemical \& Engineering Data, 1995, 40(2), 462.

18. O. Redlich, A.T. Kister, Industrial \& Engineering Chemistry ,1948, 40(2), 345.

19. Z.P. Visak, A.G. Ferreira, I.M. Fonseca, Journal of Chemical \& Engineering Data, 2000, 45(5), 926.

20. S.P. Šerbanović, M.L. Kijevčanin, I.R. Radović, B.D. Djordjević, Fluid Phase Equilibria, 2006, 239(1), 69.

21. I.R. Radović, M.L. Kijevčanin, E.M. Djordjević, B.D. Djordjević, S.P. Šerbanović, Fluid Phase Equilibria, 2008, 263(2), 205.

22. P. Jain, M. Singh, J. Chem. Eng. Data, 2004, 49(5), 1214.

23. S. Sharma and M. Makavana, Fluid Phase Equilibria, 2014, 375, 219.

24. Dikio, E.D., Oriental Journal of Chemistry, 2014, 30(3), 953.

25. S.A. Salman, S.A. Al-Khfaji, K.I. Hussain, Z.A. Al-Dulaimy, A.M. Abbas, D.T.A. Al-Heetimi, RASĀYAN Journal of Chemistry, 2018,11(2), 589.

26. C. Yang, P. Ma and Q. Zhou, Journal of Chemical \& Engineering Data, 2004, 49(4), 881.

27. A.K. Nain, P. Chandra, J.D. Pandey, S. Gopal, Journal of Chemical \& Engineering Data, 2008, 53(11), 2654.

28. J.A. Al-Kandary, A.S. Al-Jimaz, A.H.M. Abdul-Latif, Journal of Chemical \& Engineering Data, 2006, 51(6), 2074.

29. J.G. Baragi, and M.I. Aralaguppi, The Journal of Chemical Thermodynamics, 2006, 38(12), 1717. 